\title{
Occurence of Cysticercosis in cattle and buffaloes and Taenia saginata in man in Assiut Governance of Egypt
}

\author{
*Basem, R. N. Abdo, **Amal S.M. Sayed, **Asmaa A.A. Hussein, *Mohsen, I. Arafa \\ * Animal Health Research Institute, Assiut, Egypt \\ ** Dept. of Animal Hygiene and zoonoses, Fac. Vet. Medicine, Assiut University, Egypt
}

\begin{abstract}
Taeniasis is an important foodborne parasitic disease worldwide. This study aimed to determine the occurrence of cysticercosis in cattle and buffaloes and discussing its public health importance in Assiut Governorate, Upper Egypt. The occurrence of cysticercosis among examined cattle and buffaloes was $1.6 \%$ and $0.8 \%$ respectively. Female cattle and buffaloes were more susceptible to bovine cysticercosis $(2.7 \%$ and $1.3 \%)$ than males $(1.4 \% \& 0.5 \%)$, respectively. There was a positive relationship between the age of the examined animals and the occurrence of bovine cysticercosis. The higher occurrence was recorded among cattle and buffaloes above 2 years $(2.7 \%$ and $0.9 \%)$ than those below 2 years $(1.1 \%$ and $0.6 \%)$, respectively. Detailed meat inspection showed to be sensitive $(1.6 \%)$ than routine meat inspection (1.4\%). Taeniasis was detected in $0.6 \%$ of examined patients with gastroenteritis. The infection rate of taeniasis among males was $1.6 \%$ while, it was not detected in females. In conclusion, results obtained in this study confirm that cysticercosis is endemic among cattle and buffaloes. Detailed meat inspection is recommended than routine meat inspection.

Keywords: Foodborne parasite, Cysticercosis, Taeniasis, Zoonosis.
\end{abstract}

\section{Introduction}

Taeniasis is the intestinal infection of human with the adult stage of the tapeworm of the genus Taenia (Beneson 1990). There are three identified species of Taenia named, T. saginata, T. solium and T. asiatica (Andreassen 1998). About 100 million people worldwide may be infected with either T. saginata or $T$. solium (FAO 1991).

Taenia saginata known as beef tapeworm because beef is the main source of infection and it has a cosmopolitan distribution and it causes anorexia, loss of weight, abdominal pain and digestive upset (Andreassen 1998).The economic significance of Cysticercus bovis on the livestock industry may be considerable especially in developing countries. Downgrading and condemnation of the carcasses leads to substantial loss in livestock industry. Cattle and buffaloes represent the main reservoirs for human infection with T. saginata (Hughes et al., 1993).

The annual losses in cattle feed lots in South Africa due to cysticercosis may reach to $3,300,000$ US\$ per year (Dorny et al. 2002). In Assiut Governorate, the economic losses in cattle and buffaloes feed lots during 1989-1992 due to Cysticercus bovis were
112000 L.E. (Nassar and Abou-El Ala 1994). Therefore, this study aims to survey the occurrence of cysticercosis in cattle and buffaloes and investigate the occurrence of taeniasis in human in Assiut Governorate, Upper Egypt.

\section{Materials and Methods}

Detection of cysticercosis in animals:

The present study was carried out during the period between May, 2006 and June, 2007. A total of 878 slaughtered animals were selected randomly for this study from Assiut Governorate, Upper Egypt. These animals included 510 cattle with age ranged from 1.55 years (436 males \& 74 females), 268 buffaloes with age ranged from $1.5-5$ years (192 males \& 76 females). Each slaughtered animal was examined with both routine and detailed visual inspection measures (Gracey et al., 1999). The viable cysticerci were carefully removed from their connective tissue capsule then compressed between two glass slides and examined by (10x) objective lenses of the microscope. Detection of taeniasis in human:

Stool samples were collected from 325 patients (201 males and 124 females) suffering from gastrointestinal disturbances, who attended major 
Occurence of Cysticercosis in cattle and buffaloes and Taenia saginata in man in Assiut Governance

Table-1. Occurrence of Cysticercus bovis in cattle and buffaloes

\begin{tabular}{|l|l|l|l|l|l|l|l|l|l|}
\hline \multirow{2}{*}{$\begin{array}{l}\text { Snimal } \\
\text { Sample }\end{array}$} & \multicolumn{3}{|c|}{ Male } & \multicolumn{3}{c|}{ Female } & \multicolumn{3}{c|}{ Total } \\
\cline { 2 - 10 } & $\begin{array}{l}\text { No. of } \\
\text { examined }\end{array}$ & $\begin{array}{l}\text { No. of } \\
\text { infected }\end{array}$ & Percent & $\begin{array}{l}\text { No. of } \\
\text { examined }\end{array}$ & $\begin{array}{l}\text { No. of } \\
\text { infected }\end{array}$ & Percent & $\begin{array}{l}\text { No. of } \\
\text { examined }\end{array}$ & $\begin{array}{l}\text { No. of } \\
\text { infected }\end{array}$ & Percent \\
\hline Cattle & 436 & 6 & 1.4 & 74 & 2 & 2.7 & 510 & 8 & 1.6 \\
Buffaloes & 192 & 1 & 0.5 & 76 & 1 & 1.3 & 268 & 2 & 0.7 \\
\hline
\end{tabular}

Table-2. Age distribution of Cysticercus bovis among cattle and buffaloes

\begin{tabular}{|c|c|c|c|c|c|c|}
\hline \multirow{2}{*}{ Type of animal } & \multicolumn{3}{|c|}{ Below 2 years } & \multicolumn{3}{c|}{ Above 2 years } \\
\cline { 2 - 7 } & No. of examined & No. of infected & Percent & No. of examined & No. of infected & Percent \\
\hline Cattle & 361 & 4 & 1.1 & 149 & 4 & 2.7 \\
Buffaloes & 156 & 1 & 0.6 & 112 & 1 & 0.9 \\
Total & 527 & 5 & 0.9 & 261 & 5 & 1.9 \\
\hline
\end{tabular}

hospitals in Assiut Governorate [El-Eman hospital (120 patients), El-Matieea hospital (100 patients) \& El-Ezeia Village health center (105 patients)].Each sample (10 g) was collected in clean labeled plastic container with snap-on lids. Samples were fixed using $10 \%$ formalin saline solution in a ratio of 3 parts fixative to 1 part faeces and stored in labeled vials at room temperature until examination.Stool samples were examined microscopicaly with both direct smear and simple gravity sedimentation techniques (Urquhart et al., 1994).

\section{Results and Discussion}

The obtained results are recorded in the table 14. Taeniasis is an important foodborne parasitic diseases worldwide, not only for their economic impact on livestock industry and international trade of cattle and buffaloes but also for the cost of diagnosis and treatment of the infected patients. In this study the occurrence of Cysticercus bovis reported among 510 examined cattle in Assiut Governorate was $1.6 \%$ by using detailed meat inspection (Table1). This finding is considered higher than that previously recorded by Haridy et al., 1999 (0.23\%) and Rodriguez-Hidalgo et al., $2003(0.37 \%)$. On the contrary, the occurrence of C. bovis obtained in this study was lower than those reported by Oryan et al., 1995 (7.7\%); Dorny et al., 2000 (3.09\%); Dorny et al., 2002 (6.1\%); and Opara et al., 2006 (26\%).

The occurrence of $C$. bovis among 268 examined buffaloes in Assiut Governorate was $0.7 \%$ by using detailed meat inspection (Table 1). The obtained result was relatively higher than that recorded by Haridy et al., 1999 (0.14\%). On the contrary it was lower than those reported by Pramanik et al., 1984 (2.3\%).The variation in the reported prevalence rates are expected matter due to several factors such as climatic variations between the localities, number of the collected sample as well as control measures and eradication programs in such countries.
The occurrence of $C$. bovis in cattle in the present work was higher than that reported in buffaloes «Table $1 »$.Our result coincides with the result recorded by Pramanik et al., 1984. Low infection rate of buffaloes may be explained as a result of their high resistance to parasitic infection.

The occurrence rate of bovine cysticercosis in cattle varied according to the sex from $2.7 \%$ in females to $1.4 \%$ in males (Table 2). The obtained results coincide with Dorny et al. (2000). However, Pramanik et al. (1984) and Okafor (1988) in their studies found no significant differences in the recorded prevalence between sexes of the animal.

Data showed in Table 1 indicated that the occurrence of bovine cysticercosis was higher in female buffaloes $(1.3 \%)$ than male buffaloes $(0.5 \%)$. The higher susceptibility of female cattle and buffaloes may be due to the fact that females are presented for slaughter at older age than males after the end of their breeding and milking period, while, males are fattened for a short period indoors and are fed mainly on dry ration until their slaughter which reduce the chance of contracting the infection (Dorny et al., 2000).

Regarding to the age distribution of bovine cysticercosis among cattle (Table 2), high occurrence $(2.7 \%)$ was estimated among cattle above 2 years of age and it was $1.1 \%$ in cattle below 2 years. These results agreed with that reported by other investigators Pramanik et al. (1984), Okolo (1986) and Dorny et al. (2000). However, Oryan et al. (1995) found no variation in the infection rate in animals according to the age. In buffaloes, the infection rate was higher in older animals $(0.9 \%)$ than in young animals $(0.6 \%)$. The positive age correlation may be due to the cumulative exposure of animals above 2 years to the different sources of infection.

The distribution of $C$. bovis in different organs of the examined cattle and buffaloes (Table 3) showed that the predilection seats of $C$. bovis were in the heart 
Occurence of Cysticercosis in cattle and buffaloes and Taenia saginata in man in Assiut Governance

Table-3. Occurrence of $C$. bovis in different organs of the examined cattle and buffaloes

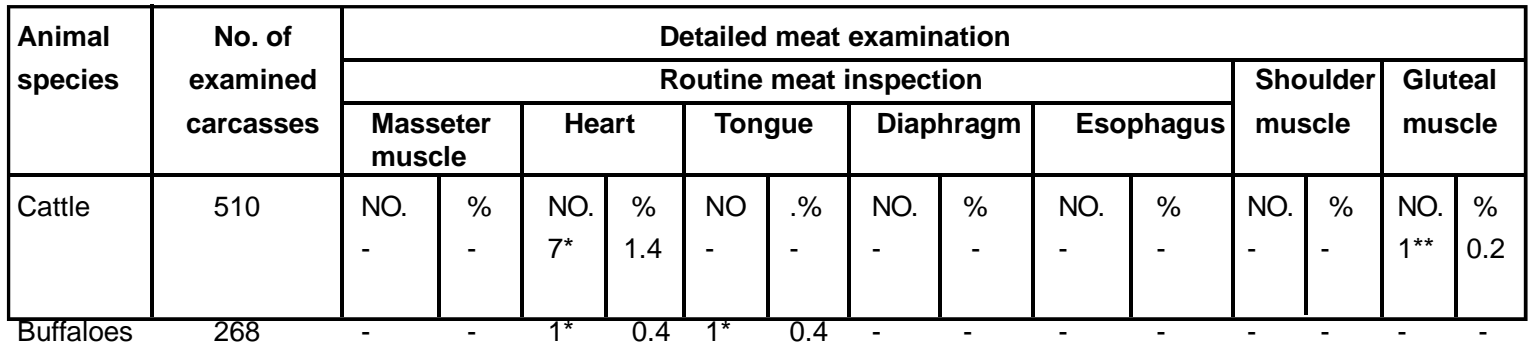

Note: The Occurrence of $\mathrm{C}$. bovis by detailed meat examination was $1.6 \%$, while with routine meat inspection was $1.4 \% . \quad *=$ nonviable Cysticercus bovis

$* *=$ viable Cysticercus bovis

Table-4. Occurence of Taenia saginata in Human

\begin{tabular}{|l|c|c|c|}
\hline Sex & No. of Examined & No. of Infected & $\%$ \\
\hline Female & 201 & - & - \\
Male & 124 & 2 & 1.6 \\
Total & 325 & 2 & 0.6 \\
\hline
\end{tabular}

of cattle $(1.4 \%)$ and buffaloes ( $0.4 \%)$ followed by the tongue $(0.4 \%)$ in cattle and lastly the gluteal muscle $(0.2 \%)$ in cattle. However, Morshdy and Saleh (1992) mentioned that the highly infected organ was the heart followed by the fore quarter. Moreover, Oryan et al. (1995) reported that the most common seats were the muscles of the shoulder followed by masseter muscle. The variations in the predilection seats may be attributed to the different management practices of the animals in such areas like using the cattle and buffaloes in the daily agricultural activities which in turn influence the distribution of the cysticerci. It is important that whatever the priority of the predilection seats we should examine the carcasses in details and not depends only on the inspection of the heart, tongue and the masseters.

The data illustrated in (Table 3 ) showed that routine meat inspection revealed $1.4 \%$ of $C$. bovis in cattle while, the occurrence with detailed meat inspection was $1.6 \%$. High infection rate was recorded in gluteal muscle $(0.2 \%)$ while, it was not detected in the masseter and the oesophagus. Therefore, it is advisable to examine the thigh muscle for detection of $C$. bovis regardless the presence of the infection in the heart and masseter or not. Although such incisions of thigh may lower the marketability of slaughtered carcasses, but it is more safe for human health.

Concerning to the viability of the cysticerci (Table 3 ) most of the detected cysticerci $(90 \%)$ were dead. This finding may be due to the fact that cysticerci become dead and calcified after 9 months post infection (Lloyd 1998).

The occurrence of taeniasis among 325 examined patients in the present work was $0.6 \%$ by using sedimentation stool examination technique (Table 4). The recorded result was lower than that reported by Buchy, 2003 (0.75\%) ; Martinez-Maya et al., 2003 $(1.2 \%)$ and Culha, $2006(0.7 \%)$ and The differences may be due to difference in the location of the study, as well as personal hygiene, educational level, control and eradication programs in such localities. The infection rate was $1.6 \%$ in males while, it was not detected in females.

\section{Conclusion}

Results obtained in this study confirm that cysticercosis is endemic among cattle and buffaloes. Eradication of bovine cysticercosis requires cooperation between the public health and official veterinary authorities. Public health education is considered the key factor for control of taeniasis and cysticercosis. Detailed meat inspection is recommended than routine meat inspection.

\section{Acknowledgement}

Authors are sincerely greatful for the great help of members of Parasitology Dept .Faculty of Medicine at Assiut University for their great help and advice.

\section{References}

1. Andreassen, J. (1998): Intestinal tapeworms. In Topley \& Wilson's, Microbiology and microbial infection, $9^{\text {th }}$ ed., Oxford University press Inc., New York. Volume (5): pp. 521-537.

2. Beneson A. (1990): Control of communicable diseases in man. $5^{\text {th }}$ Ed., American public health association, Washington, DC. pp. 427-429.

3. Buchy, P.(2003): Intestinal parasitoses in the Mahajanga region, west coast of Madagascar. Bulletin de la Societe de Pathologie Exottique, 96(1):41-45.

4. Culha, G. (2006):The distribution of patients with intestinal parasites presenting at the Parasitology Laboratory of the Mustafa Kemal University Medical Faculty. Turkiye Parazitolojii Dergisi, 30(4):302-304. 
Occurence of Cysticercosis in cattle and buffaloes and Taenia saginata in man in Assiut Governance

5. Dorny, P. et.al.(2000):Sero-epidemiological study of Taenia saginata cysticercosis in Belgian cattle. Vet. Parasitol., 88(1-2):43-49.

6. Dorny, P. et.al.(2002):A sero-epidemiological study of bovine cysticercosis in Zambia. Vet. Parasitol.,104(3):211-215.

7. FAO (1991): Report of the FAO expert consultation on helminthic infections of livestock in developing countries (AGA, 815), FAO, Rome, pp. 16-17. Cited in Andreassen, J. (1998): Intestinal tapeworms. In Topley \& Wilson's, Microbiology and microbial infection, $9^{\text {th }}$ ed., Oxford University press Inc., New York. Volume (5): pp. 521-537.

8. Gracey, J.F. ;Collins, D. S. and Huey, R.J. (1999): Meat Hygiene, $10^{\text {th }}$ Ed., Harcourt Brace and Company Limited, 24-28 Oval Road, London NW1 7DX. pp. 673-678.

9. Haridy, F.M.,et.al.(1999): Human taenaisis and cysticercosis in slaughtered cattle, buffaloes and pigs in Egypt. J. Egypt Soc Parasitol, 29(2):375-394.

10. Hughes, G. et.al.(1993):Seroepidemiological study of Taenia saginata cysticercosis in Swaziland. Res. Vet. Sci., 55(3):287-291.

11. Lloyd, S. (1998): Cysticercosis and Taeniosis Taenia saginata, Taenia solium and Asian Taenia: In Palmer, S.R.; Soulsbay, E.J.L. and Simpson, D.I.H. : Zoonoses, Oxford University press Inc., New York. pp. 635-649.

12. Martinez-Maya, J.J. et.al.(2003): Taeniasis and detection of antibodies against Cysticercus among inhabitants of a rural community in Guerrero State, Mexico. Salud Publica de
Mexico, 45(2):84-89.

13. Morshdy, A. and Saleh, R. (1992): Incidence of cysticercosis in slaughtered cattle in Gassim region. Zagazeg Vet. J., 20(5): 727-731.

14. Nassar, A. and Abou-El Ala, A. (1994):The public health importance and economic losses of cysticercosis in slaughtered animals in Assiut province. Assiut Vet. Med. J. 30(60): 165-169.

15. Okafor, F.C. (1988): Epizootiology of Cysticercus bovis in Imo state, Nigeria. Angewandte Parasitologie, 29(1):25-30.

16. Okolo, M.I.(1986):Studies on Taenia saginata cysticercosis in eastern Nigeria. Int. J. Zoonoses, 13(2):98-103.

17. Opara, M.N. et.al.(2006): Cysticercosis of slaughter cattle in southeastern Nigeria. Ann. NY Acad. Sci., 1081:339-346.

18. Oryan, A.; Moghaddar, N. and Gaur, S.N. (1995): Taenia saginata cysticercosis in cattle with special reference to its prevalence, pathogenesis and economic implications in Fars Province of Iran. Vet. Parasitol., 57(4):319-327.

19. Pramanik, A.K.; Bhattacharyya, H.M. and Sengupta, D.W. (1984): Occurrence of $C$. bovis in slaughtered cattle and buffaloes in Calcutta and its public health significance. Indian $\mathrm{J}$. of Anim. Hlth. 23 (2): 141.

20. Rodriguez-Hidalgo, R. et.al. (2003):Taeniosiscysticercosis in man and animals in the Sierra of Northern Ecuador. Vet. Parasitol., 118(1-2):51-60.

21. Urquhart, G. M.et.al. (1994): Veterinary Parasitology, Longman Singapore Publishers Pte Ltd, Singapore. pp. $269-271$.

\footnotetext{
$* * * * * * * *$
} 